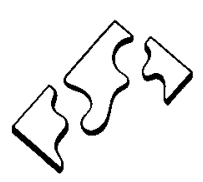

36

\title{
Human Science as a Dialogue with Children'
}

Ton Beekman

Rijksuniversiteit Utrecht

Contemporary science can be seen and described as a production process. There is both an input with an investment in manpower, time, facilities, and an output with a product: knowledge. In such a model one accumulates this knowledge and stores it in articles, books, libraries, abstracts, and computers. The output can be measured in a so-called evaluation of objectives whose outcomes are predictable. Hence one necessarily develops objectives of a certain kind: that is, objectives that have predictable and measureable outcomes. In this view, science becomes a technological tool: in the natural sciences a tool for controlling nature, and in the social sciences a tool to use in controlling human beings. Too often this is the case in educational science. One has to produce practical tools: for example, programs for reading and, as a part of those, tests to evaluate those programs. Effects can then be measured ensuring that the desired outcomes have in fact been attained. One uses these programs to control: in particular, to control powerless people like children, inmates, or handicapped people. Even teachers and professors are not free from the controlling impact of these tests.

However, there are some practical problems with pursuing this model. Too often it brings us (in order to maintain the "hard," "quantifying" approach) to strange, alienating conclusions: for example, the assumption that if reading scores are higher, the school system really is a more effective learning environment. This strange kind of thinking (strange only if you reflect upon it) affects our way of looking at schools and children when we try to fit the everyday reality that we experience into the tiny dimensions of our poor models.

In the area of so-called "moral" education, rather than attempting to understand children's real ethical dilemmas, we see only moral development inventories as outlined by Lawrence Kohlberg and other experts. This narrow way of seeing affects the daily reality of our "professional" interaction with our "subjects," be they children or other "powerless" individuals. Real people become program-dependent entities!

An alternative vision for social science may be more helpful, more concerned with human interests. ${ }^{1}$ A little anecdote may illustrate my point further: Erwin Strauss once told the story of a professor who invited ten guests for dinner. When two extra people unexpectedly arrived, he was both embarrassed and concerned about the quantity of food he had prepared. However, when this same man anticipated twenty people for a lecture he was to deliver, and there were forty people in the audience, he was not embarrassed. Indeed, he felt gratified by the good response. Hence we see that scientific knowledge cannot be conceived as a static stock of deposits, filed away in a storeroom. Rather, it is constituted as a freely given relationship among people.

Science is fundamentally a "social" phenomenon. It is a dynamic relationship among people who talk and write for an audience of fellow 
researchers, students, interested lay people, and readers. In this view, science is a discourse, a dialogue. It is not a dialogue initiated just today, but one that began long ago: one steeped in a history of tradition. Science has its institutions, departments, libraries, journals, and often its own "language." A new disciple always waits to be socialized in these ways. Students have to learn the norms, the values, the rituals, and the mores of the group they wish to join. Once they are accepted, and after the appropriate initiation ceremonies, they are entitled to participate in the rituals of the tribe. We see how, historically, sciences have tended to be very oligarchical and hierarchical and that, despite a kind of truthrhetoric, the lived morals have been very conservative. Even in Kant's time during the nineteenth century, the regulations for doctoral dissertations in Koningsberg stated that "nil novi" (nothing new) dared to contend. There has been change since then, but not much. There is much talk of creativity, but little action by faculties to see that it is nourished. Rather, it is product-evaluation that receives sustenance.

If one examines the evolution of science, one sees that it is fair to say that science has come more and more to mean "natural science" with its scientific practical realization, technology. Thus, science has become more and more a powerful tool able to change our world but less insightful with regard to human life and its multiple forms and meanings.

Science as technology has changed the world we live in: for the better in some respects, but certainly not in all. As science has become a less gerontocractic, aristocractic affair, it has also become a more meritocratic enterprise, and universities have become a competitive jungle. And who are the beneficiaries? We are asked to believe that every advance in science and technology has potential benefit for humankind. But, too often it appears that these benefits go to the already rich and powerful. We seem to practice a kind of "trickle down" theory of science. If social science wants to be different, to be a human science, it seems appropriate to consider more carefully how to make the people of our research partners in the dialogue.

Shall we give our subjects an equal voice? Would that be a more democratic science? But what, if they don't know what to say? If they cannot speak? If they are children? It seems that an egalitarian, democratic dialogue is not always possible. People are simply not the same-certainly not in the scientific dialogue. To advocate egalitarianism as a general approach would be both naive and unrealistic. What we plead for is a more careful, "caring" analysis of the diverse possibilities inherent in the dialogue between adults and children. Let me make clear that neither a meritocractic nor a technological approach can fulfill the requirements of a dialogue. Such an approach is imposed from above. Most "forced choice" interviews, for instance, are of this type. In these, we ask only for what we think is important, what fits into our model or theory. We keep our subjects in the dark about our intuitions, which we call hypotheses. By not disclosing the truth of our intentions for fear of contaminating our data, we display a contempt for 
the dignity of our subjects. Very often we transgress even further, perpetuating poorly hidden, or even direct, insult or abuse. It is too easy in this way to misuse their understanding of events to fit our own beliefs about what is important.

I think it is better to start by participating in the daily life and the interests of our informants. That is the place where dialogue can start. And if we are not accepted there, on that common ground, what right do we have to go on?

Part of our participation in the lifeworld of our informants involves intimate, detailed observations that constitute "thick description" narratives which are both systematic and reflexive. Our conversations, too, are intentional, directed dialogues, respectful of the competence of our informants. But is that not more an ethical imperative than a methodological prescription? The question supposes a gap between methodology and value-realization. Is that gap justified? Or does it make clear how far away from the issues of normal life science has drifted?

Perhaps, before we make any abstract analysis or use a typifying example of the scientific enterprise, it would be advisable to look at a concrete example of research. Our research group in Utrecht has an ongoing interest in children's experiences of space in their daily lifeworld. Maybe we can elucidate our questions about the way to proceed in creating a scientific dialogue by focusing on the everyday life experiences of children.

What is the landscape of a child like? Can I, as an adult observer, describe the spatial world of children? Can I describe my own? Let me start with a fragment from my own landscape as I travel to a childcare center here in Ann Arbor. I can give you my plan of Ann Arbor, different from yours because I don't drive, but, at the same time, sufficiently conventional for you to understand. Indigenous Ann Arborites know most of the street names and markers on my route: Island Drive, Maiden Lane, Kroger's, the crazy intersection at Broadway, the bridge across the river, the railway station you drivers barely see but nevertheless know is there, then South Division, and Packard. Is this the same structure for young children? Does the young child see with the same eyes?

I can also describe the way I see a childcare center that I visit: the entrance way lined with "cubbies," the play areas, the quiet room, the group spaces with tables and little chairs, the "get-together" area, the basement with all the gymnastic equipment, and the swings. I can give you the dimensions in square feet. If I kept track, I could give you frequency counts for each of these areas, the numbers of children and their ages.

Why, then, speak of dialogue? Does that not "mess" things up? Maybe it would be better to observe the children from behind a one-way screen! For does my presence not change their behavior? Seeing, but 
not being seen; hearing, but not being heard, that would be objective, quantifiable, reliable, and replicable. But would I understand?

I would be like the observers of a playground in Holland, counting their own made up categories but not understanding. This is described very clearly in Kinderen buiten spel (The Play of Children Out-ofDoors) where so-called objective observers went inside an unobtrusive workmen's shack, made a peeping hole, and made coded objective observations. In their protocols we find scores of "activities" numerically coded. The meaning of the experience is missing. For instance, if you were really "in" the park, you would see girls hanging around on bikes. Doing nothing? Or being social? How do you know, until you are really out there, interacting with the children?

It is easy to understand that I have to be there "in" the social context. That means being part of it, participating, interacting, changing, being changed, sometimes questioning. What then will I discover?

When I travel to the daycare center, I know where I am going. But my three-year-old companion sees only clues-the tops of houses and trees. He is not dependent on time as we are but rather is persondependent. Children accept what happens when they arrive. I walk in by myself, the child is often carried in.

But a three-year-old can be very afraid in that big empty space, dropped out-of-the-blue from home into a different world with bigger children, the loud masters of the daycare center, even defying orders from adult teachers. Where can you hide? Sometimes you can play quietly in a corner, but sometimes a "big one" comes and takes it away. The bigger children don't ask you to join with them in their play. You are left out. For example, a typical winter day might include, if you are a little one, going downstairs in the morning and seeing that the swings are taken, the climbing racks are full, and so you run off by yourself.

The little ones enjoy that basement much more after snack-time because then the bigger children go upstairs and the basement becomes their place. They can make a house without the big girls interfering with them. The little play kitchen is a fantasy of delight. It is only a suggestion of a kitchen with some play cups, but it determines the meaning of a whole area as a "possible house," which is very typical of a child's meaning for this daycare area.

Then there is the quiet room. For a lot of children this is the room where Grandma Millie will read your favorite book. This is a good example of how social and personal meanings come together; for it is a social space where every child can have a story read to them, and they can also bring their favorite book with their personal, sometimes very private meanings. "Madeleine" and the ongoing epic of Miss Clavell and her "disasters" is one such favorite.

It is this theme of the personal-social topography of a child's world that makes a phenomenological study different from the typical ethnographic approach. The ethnographic study is centered on cultural 
or subcultural meanings. It aims at a taxonomy, an inventory of cultural meanings: for instance, how the "get together" place and the 10:30 a.m. time have important social meanings for teachers because they are part of a program; for children, it is different since they don't know how the day is planned, but they do know that there they sing your birthday song, there you can show and tell, and there you do fingerplays and listen to a story. For educational science this ethnography is almost a necessity enabling us to become aware of these meanings. As teachers we should know our own social landscape reflexively: How "upstairs" is the place where we can escape the ongoing pressures of "downstairs." But we also have to know how radically different our world is from the children's point of view, where "upstairs" is a "nowhere land," a place where grownups disappear, and where the "get-together" place is the central feature of the landscape.

However, to be generally aware is not sufficient. We have to be attentive to the personal and the private worlds of children, too. We had better know each child as a unique individual. Wendy is a very shy child who tries desperately to be noticed at the "get-together" place where she sits in the shadow of the room divider between that partition and my body. For her, Monday's get-together means sitting in that "safe place" and "talking with me," daring to reach out only a little bit, as I encourage her to try.

To understand her view of things, it is necessary to have a close and intimate rapport with her. It is then that $I$ become aware of the personal meanings that places hold for the children. As a rule, one discovers this only in an ongoing relationship which allows an expressive dialogue to take place. Only in this way can we learn to appreciate some of the fundamental differences in lifeworld structures of young children and adults, precisely because children's worlds are largely pre-conventional. As long as we see the actions of little children through the models of our shared adult conventionality, we are not likely to see the world as children, in their own uniqueness, see it. Nor are we likely to see children, themselves, very clearly. Using our adult theoretical lenses, we see a "not yet" adult, an immature, egocentric subject, with a prelogical approach to the world, who can only see reality anthropomorphically. This view contrasting the child's world with our adult world is not a good measure of the young child's world. In our adult world we share many of our conventional meanings in language. We have, by means of signs and language, created a conventional landscape independent of any actual experiences and actions. Such a shared cultural landscape is often useful, but also often deficient. With my adult goal orientation, I am frequently not "here" where I really am. Going to the School of Education, I sometimes mentally project in time to the seminar about to take place. What I don't see is that the painters have altered the roof and painted the walls of the corridor. But Sasha, a three-year-old, told me. He is not hindered by adult projections "far away" into the future. Conventional meanings hinder what we see, whereas the child's landscape is more immediate and more exciting-full of colors and changes which I, as an adult, don't notice. 
Thus, the question for us becomes "What are the boundaries for a very young child?" Being a child means that you are dependent on adults for your actual landscape. They "transport" you where they want you to go, and your grip on the world is very limited in this respect. The child's orientation in space is very often person-oriented or action-oriented. For the little ones at the daycare centre, "downstairs" is the place where they follow the teacher, where Grandma Millie is, and where they wait for me to play "ghost."

In unfamiliar places, we perceive even more clearly how action and person-determined a child's sense of space is. Another observation illuminates my remark: At the airport, there is a waiting crowd at one of the larger gates. A two-year-old wanders among the large grown-ups who are attentively watching the gate. The child is curious, walking around in a small circumference- 5 or 6 feet. For him, this is a real walk. And every minute he looks back to check that his father is there. He walks back to him and then goes off again, well satisfied with this exciting world around him, new and full of life. The crowd does not bother him it seems; he is self contained. Using his father as a central reference point, he does not experience the crowd; for his boundary is set in the relationship between his father and himself. While places are largely adult-determined, the personal meanings of the social space can be very different for the child and will vary according to different children's experiences.

We see, too, how all places are also emotion-bound. Wendy in the daycare center, becomes shy as the room changes to the "get-together place." Sasha, as observed by his mother, begins to experience darkness as a fearful phenomenon:

He began to refuse to sleep without a light, would not stay alone in a darkened space, and felt a deep sense of unease when confronted by shadows, the upstairs, the downstairs, approaching night, and spaces in which he was alone. All these took on a new form as

Sasha became aware of their threatening properties:

Sasha and Shael (his brother) are playing on the livingroom floor in April:

Sasha: Somebody's going to come up from de basement and make you frightened.

Shael: Nobody is in the basement-you don't have to be frightened.

(Tickles him-laughter.)

Sasha: Somebody's going to come up from de basement.

Shael: Who is somebody?

Sasha: De shadow.

Shael: You don't need to be frightened of shadows-they're just like paintings on the wall and they move. 
Sasha: (Looks at the wall) De paintings are like shadows?

Shael: Yes, on the wall, and they move.

Sasha: De shadow come up from the basement?

Shael: No, they won't, they're always on walls or outside.

Shael plays an important role of reassurer in mediating the fears which often transform Sasha's social space, making of it something other than it appears to us as adults.

Ophelia, the dog next door, old, rather decrepit, and certainly harmless, literally has a bark far louder than any bite she could muster -yet for Sasha, 'phelia symbolizes the malevolent, possessing mysterious powers of jumping through glass windows, appearing in bedrooms, lying inside toilets, and even climbing into cribs. Ophelia - the loud bark and the darkness of night come together in some fearful way to lend an aura of the lurking unknown to Sasha's night. Ophelia - the very stuff out of which Sasha's nightmares are fashioned-has a reality qualitatively different from that of our adult world (Suransky, 1982, pp. 3-29).

All these aspects of a social/personal/private landscape are not observed from outside. One has to go inside the child's landscape. It is almost impossible to discover what the "house" means to a child unless you engage in a dialogue with the child in the house. And the dialogue has to be an ongoing one in which the child can talk freely with you at his or her own level. When the child shows you secret places and sometimes admonishes you with "You cannot come in here," then you know you are accepted.

The dialogue is also context-bound and dependent on my initiation and invitation as an adult. In the basement of the daycare, I begin to understand the children's liking for soft blankets only if I make them available. If they trust me, we can discover together how nice and cozy it is to make a tent with my arm holding up the blanket and in the halfdark to see each other's eyes shining. That was my initiative. A week later a child says, "Let's make a tent," and he gets a blanket. We could call that a delayed response into the ongoing dialogue. And again our eyes met in the half-dark. Another week later I see that he and the other children want the teacher to join them in their tent, and together they all giggle in the secret place.

In the case of children, dialogue means observing and interacting in security, at ease, with patience, and without imposing on them.

We as adults ask little children all kinds of questions. As I get in the car, I might ask Sasha about some things that interest me. In the conventional adult world he would at least try a response, but today he is not in the mood. "You cannot talk to me," he announces moodily. Accepting that can be the start of a dialogue. It isn't much of a basis for 
experiments, but it could be a good basis for phenomenological research. We can discover how much adults impose themselves and their intentions on children.

The psychology of children has developed as an enterprise of adults who were interested in studying "how a child becomes an adult" or "how can we effectively, or more efficiently, teach children?" Both interests are sometimes legitimate. But is it not more legitimate to discover how children are? They are among other things, very worthwhile, competent partners in a dialogue. I can assure you I look forward to every Monday when I go to "my" daycare. Leaving my adult concerns behind, I discover the joys and sorrows of my companions, competent actors in a world where they are nevertheless dependent, in many respects, on adults. They don't have a choice about whether there will be a snacktime or what sort of snack they will get. But they know exactly what they like, what they don't like, and how to handle these adults through refusal of the snack. Of course, certain adults could force the children to eat some things by saying that they are "good for you." But how would we like it if someone did that to us?

In this way, we see how much of the child's world is an adult-caredependent-world. Little children's worlds are certainly social worlds, but they are social in a less culturally determined sense. Our actions are very much shaped by culture and convention. The impact of these actions on children are personal, private, and unique: very much preconventionalized. To a child the classic story of "Madeleine" becomes the story of "Miss Clavel" and the night-time disaster even though it is clear to us that the author meant Madeleine to be the main character. Where darkness has hardly a name, and shadows are more than just shadows, the evidently harmless old dog "Ophelia" becomes a sinister barking creature.

The child's world is a world of senses, emotions, and actions: where "second nature," culturally determined meanings have not yet taken over the direct experience; where the outside world is an invitation to action; where a long tunnel is not merely a tunnel but an enticing mysterious shape that beckons a child to stamp and shout with resounding echoes.

For these reasons it is a world of wonder and of discovery. It is different from an artist's wonder for the artist is both reflective and selfconsciously expressive, writing or painting for an adult audience. The child's world is less goal oriented, and there is a fuller presence in the experience of now. It is a vulnerable world. Some children retreat from it very early into a private world, or they vacate this world to put on a goal-oriented work harness as portrayed in the "thick description" narratives of the The Erosion of Childhood, where the bureaucratization of childhood is seen taking place in Montessori and profit-run daycare centers.

The child's world is also a world of reflective and thoughtful beings: of philosophers, as we see in Gareth Mathews' Philosophy and the Young Child, and of moral actors, as we read about Ruby in Robert Coles' Children of Crisis. 
There is for us a vast landscape waiting to be understood. We can begin by describing the social topography, the social geography of children's worlds citing the multiple and rich features that are part of the landscape in the life of a child.

We observe how time and space are action and person bound: how the act of discovery engages children in constant experimentation and transformation of their landscape; how instant changes of mood are part of a private and social world which is less conventionalized; how the awareness of objects as beckoning invitations to action transforms the environment into a very sensual, colorful, and often frightening landscape of experience.

Thus, by immersing ourselves in the culture of childhood, we gain measureless insights into the structures of a lifeworld distinctively different from that of the adult-and often far more fascinating!

\section{Notes}

1. This article was presented at the Phenomenology of Childhood conference, University of Michigan, April, 1982. I wish to thank Professors Loren Barritt and Valerie Polakow Suransky for reading the draft of this paper and their invaluable help in editing.

\section{References}

Beekman, T. and Mulderij, K., Beleving en Ervaring. Amsterdam: Boom, Meppel, 1977.

Bleeker, H. and Mulderij, K., Kinderen Buiten Spel. Amsterdam: Boom, Meppel, 1978.

Suransky, Valerie Polakow, "Sasha at Two: An Ethnographic Portrait of a WordJuggler, Storyteller, Scientist, Philosopher, Rebel." Outlook, 43, 1982.

Suransky, Valerie Polakow, The Erosion of Childhood. Chicago: Univ. of Chicago Press, 1982.

Matthews, Gareth, Philosophy and the Young Child. Cambridge: Harvard University Press, 1980.

Coles, Robert, Children of Crisis (Vol. 1). New York: Delta, 1967. 